\title{
Issue Mapping and Inquiry: Preparing College Students for the Challenges of the Changing Economic World
}

\author{
Thomas Williams, Lennart Johns, Chris Hakala* \\ Quinnipiac University, USA
}

Submission: May 26, 2017; Published: June 14, 2017

*Corresponding author: Chris Hakala, Executive Director, University Teaching and Learning and Professor of Psychology, Quinnipiac University, USA, Tel: 203 582-7807; 413 441-4452; Email: cmhakala@qu.edu

\begin{abstract}
Students need to be equipped to handle the complexity of the world they are preparing for. Leadership skills need to be developed and cultivated and students need to understand the changing demands of the current workforce. At Quinnipiac University, we have fashioned a curriculum designed to help prepare students by helping them learn to frame problems using the technique of issue mapping. In this article, we provide both a description of how to help students learn this technique and also some of the rationale for why we think this is as effective as it appears to be.
\end{abstract}

College and University students are entering a world that is different than 25 years ago. The percentage of students who obtain a college/ university degree is increasing and the demands for the skills necessary for the workforce are changing. To address these issues, Quinnipiac University has undertaking a variety of steps in re-shaping its undergraduate curriculum to help prepare students for the challenges that they are going to face. This article offers educators a problem structuring model (PSM) designed to help students better understand and approach what Senge [1] calls dynamic complexity: "situations where cause and effect are subtle, and where the effects of interventions are not obvious." By doing this, we believe we are offering students an opportunity to be at the forefront of the intellectual and practical world that they will be entering upon graduation.

Our model is an adaptation of issue mapping, which uses observations and questions to promote deep inquiry into an issue, rather than relying on simply, underdeveloped ideas. Over the course of the last year, faculty at Quinnipiac University have found issue mapping to be useful in multiple contexts and offer an easily adaptable description. We have certainly made changes since introducing the concept to our faculty in 2015, but the primary motivation remains; we want students to self-discover that education is less about the certainty of knowing answers and more about acknowledging and responding to the unknown.

The reasons for this pedagogical focus are many, but perhaps most significant is the need to train 21st century leaders with what Yawson (2015) describes as the "pattern recognition skills of an artist" as well as the intellectual flexibility, open-mindedness, and cognitive diversity necessary for handling the disequilibrium and turbulence of the post-industrial age.

Yawson (2015) is correct; students are entering an environment characterized by advances in science and technology so rapid that they often create or render obsolete global companies (or entire industries) in short order. Three iconic examples are Kodak, Polaroid (both replaced by digital cameras) and the VCR (replaced by on-line streaming services and digital formats of films and television). In fact, 88 percent of the companies that dominated the Fortune 500 list in 1955 have folded, and a modern company's lifespan is less than 15 years [2]. Now consider that these same advances mean that some of our textbooks and disciplinary content are rendered obsolete within a few years of a student's graduation [3]. It is very likely that we are preparing students for industries and careers that do not yet exist and possible that we are preparing them with soon to be dated material.

In this "Knowledge Economy", intellectual capability has supplanted physical inputs and natural resources as the driver of progress Powell, Snellman [4]. While do not define intellectual capability, and are generally cautious about next steps, a 2013 report issued by the Association of American Colleges and Universities (AAC\&U) might offer an insight into what leading business and non-profit leaders think. The AAC\&U report argued that 93 percent of these executive believe that "a demonstrated capacity to think critically, communicate clearly, and solve complex problems is more important than [a candidate's] undergraduate major"[5]. The report makes it clear that graduates lacking these abilities will be at a distinct disadvantage [5].

While it is a bit premature to discard college majors and the work each discipline does to instill these habits, we believe that by providing students with the essential habits of inquiry, integration and communication, we are giving them a competitive advantage.

Abbreviations: PSM: Problem Structuring Model; FYS: First Year Seminar; AACU: Association of American Colleges and Universities. 


\section{Quinnipiac's Approach}

In 2015 Quinnipiac launched a First Year Seminar (FYS) program, complete with learning objectives that specifically introduce these skills and capacities. The FYS course includes the need for students to foster critical thinking strategies, value cognitive diversity, and develop collaboration skills all with an eye toward the capacity to wrestle with complexity. Another key learning objective in the FYS program is that students practice is inquiry. Inquiry as pedagogy is fundamentally simple and "uses questions and problems to provide contexts for learning" [6].

At Quinnipiac we teach students that inquiry and integration are habits of mind; an educated person's outlook on and approach to dealing with complex problems. Students who develop an inquiry and integration habit of mind understand how people from different perspectives generate knowledge, how they evaluate and integrate this knowledge to create ideas and make decisions, and how they communicate to gain support for their ideas, positions, or decisions.

The FYS program borrows heavily from Rittel, Webber's [7] famous "wicked problems" construct. Students explore problems that defy simple solutions. They learn that when looking at the problem, each person's unique disciplinary, ideological, or personal values and interests make them susceptible to perception. Wicked problems are never simple dichotomies of good/bad or right/wrong. Wicked problems always require judgment and there is no single "test" of efficacy. Rather, perception often governs what is success. Students quickly realize that when dealing with wicked problems it is impossible to gain complete knowledge of all its factors. There are always more facts to find, knowledge to understand and the search for answers or approached to problems that are perpetual.

The realization that complex problems are messy and may defy solution does not absolve us of the need to take action. Yet we find that many students are conditioned to be spectators and are too willing to accept problems as presented [8]. And like many adults they jump right into an aggressive process of trying to solve the problem absent any meaningful understanding of its scope [9].

When approaching a complex problem superficially, a student may confidently and aggressively set out to solve what is a symptom, or the wrong problem altogether (resulting often in a new set of problems). Students must first recognize that in wicked problems, the relationships and interaction of all of its parts and the points of view of differing perspectives often create the complexity [1]. In short, our first impressions are often quite incomplete. Toward this end we introduce students to systems thinking, and a framework for seeing problems holistically. Our framework, our process for issue mapping, is designed to help students do more than organize their ideas, it helps them visualize those situations where the "effects of interventions are not obvious" [1].

\section{The Issue Map}

Issue mapping is a tool that helps systems thinkers frames a problem in a visual format. Issue mapping is not a problemsolving tool, but rather a way of formatting the problem to be understood from different perspectives. Issue mapping serves as a transitional object (temporary foci) to help structure engagement [10]. The intent is to help students see that many complex problems are greater than the sum of its parts. Their task in creating the map is to identify relationships and open new and previously unseen lines of investigation, or perhaps discover key leverage points that, if addressed, would have a disproportionally high impact on understanding which may also lead to better management of the problem.

The process of issue mapping is also a way to collaborate with those who might have different perspectives or world views and for the development of a common understanding of the issues and the relationship of the various issues that construct the problem [10]. The mapping we use in FYS is not quantitative, but qualitative. It's a 'soft-systems' approach meaning that it is about defining the problem, not tackling it [11].

\section{How Issue Maps work with Inquiry}

As noted, a central focus of the QU FYS program is to have students explore various "wicked" problems through inquiry. Students use issue maps as a tool in the effort to more deeply understand the problem at hand and to forge lines of investigation. Issue mapping focuses the student's attention on that which is unknown to the student. Issue maps provide a structure that helps those open lines of investigation via questions. Although Cronin, Midgley, Jackson [10] describe issue mapping as a "temporary foci", the inquiry cycle forces students to return to their maps on a regular basis to integrate new information, insights and perspectives. As their knowledge and ability to ask more complex questions improves, so too will their issue mapping skills and lines of investigation.

The map is less important than the process of mapping. A map may start with a vague topic, theme, or question. In the process of having participants identify and discuss their observations, questions, and connections, they often find the premise of their original theme too broad and start anew. Purposeful abandonment of the product is not a waste of time (and may be a required step) as the product is merely an illustration of the larger goal: visualizing the complexity and developing a shared understanding of the problem. Students (and faculty) often fail to understand the purpose behind issue mapping and therefore they struggle with the process. The confusion usually stems from their prior experience using concept maps (or mind maps) which are meant to organize existing knowledge or develop plans for a solution.

\section{Issue Mapping Supports Critical Thinking}

In addition to playing a role in the inquiry process, the practice of issue mapping is a way for students and faculty to 
strengthen what Daniel Willingham [12] calls met cognitive strategies that, once learned, increase the likelihood that students engage in critical thinking. Willingham explains that these skills include a combination of reasoning, decision making, and problem solving, but that they must be characterized by three key features: "effectiveness, novelty, and self-direction".

To be effective, he says, is to avoid the usual "common pitfalls, such as seeing only one side of an issue, discounting new evidence that disconfirms your ideas, reasoning from passion rather than logic, failing to support statements with evidence". More important to us is Willingham's comments on novelty. It is more than cleverness, more than drawing on memory to address complicated but solvable problems. He offers that "critical thinking is self-directed in that the thinker must be calling the shots: We wouldn't give a student much credit for critical thinking if the teacher were prompting each step he took" [12].

Issue mapping provides the ideal context to foster Willingham's metacognitive strategies. As wicked problems are each unique and constantly evolving, there are no formulas to guide or examples to follow. Each map is novel and as such, must result from self-directed activities. Lastly and when done properly, students must contend with and reconcile diverse perspectives and how others infer different meaning from similar evidence. Further, it is a process by which students build expertise. They integrate new knowledge into existing knowledge in ways that make it easily accessible and as they create new or see novel connections between previously unknown but related segments of knowledge they are more capable of transferring and applying their knowledge in multiple contexts [13].

\section{Issue Mapping, not Mind-Mapping}

The first step in teaching issue mapping is to help students differentiate their prior understanding of "mapping" with the new. If they do not truly see the difference, they'll quickly revert to old habits and conceptions [14]. Mind maps are visual depictions of information connected by spokes to a single idea or concept. They organize and rarely go beyond what is known. Making the shift from mind mapping to issue mapping requires repetition and practice coupled to readings, mini-lessons, discussions, and modeling. Through experience we find the more students work with each other (and their instructor) on the proper construction of an issue map, the more they selfdiscover its value and desist in their efforts to mind map, to organize the known.

\section{Getting Started}

When you are looking at the white board and wondering where to begin, write your problem statement on the board. This statement is your starting point. Your task is to visualize what makes this statement (your problem) complex. You are asking, "Why is this problem "wicked"? Next, consider is the scope of your investigation. Scope is about practicality. If some begin listing observations in one area that focus on small town's plight, but in another area a student is working on the premise that the problem is global, they will be at cross purposes no matter the quality of their work. A good illustration might be work that revolves around poverty. This is a good issue, but simply saying "poverty" is overly broad. Poverty where? Poverty in today's world, or an historical examination? A problem statement such as "can Western nations improve healthcare in Sub-Saharan Africa?" allows you to look at complexity of the forces in that region. When asking philosophical questions, such as "what is leadership" or "Is there a case for God?" or on less defined social questions, such as "education" or "healthcare" and you are trying to grapple with the many perspectives at work it is similarly necessary to decide whether they are looking at their issue from a local, national, or global perspective.

\section{Mapping is Framing}

Any internet search of the term "issue map" generates millions of hits and the realization that there is no single model or method. This can be useful in that a student is not constrained by prescription, but it can also generate confusion as some examples are about problem solving or idea organization. Our use of the term closely resembles and is adapted from a technique widely used by strategic planners called "environmental framing" [15].

Framing is about building a description of the current state of affairs that might bring new perspectives on a problem. In this process, planners try to frame their problem with the variables that appear to act on or influence the problem. These might include economic, social, cultural, political (power), technological, religious, media, geographical, or other environmental conditions. Planners know that none of these are necessarily more important than the others, and that they work together as a system. To be precise, they work as an open system. In a closed system, an action into any part of the system results in a predictable reaction in the other part. Think of a balloon. When you squeeze on one end the air that is contained within the balloon must pop out at the other end. In open systems, one cannot predict how, where, or to what effect an action or stimulus in one area will manifest in the others.

It really doesn't matter what you choose as long as taken together the nodes will help the student see their problem's full complexity. There's no set number of nodes, but we've seldom seen students start and end with the same number or type. Issue-mapping is not about building a product. It is about using a tool to illustrate complexity or build shared understanding. Add, delete, or combine nodes as the map evolves.

The systems we are envisioning with our maps are complex open systems, meaning it is the relationship between these variables, or nodes, that matters most. Students will learn that the problem did not originate in any one node and neither will the solution. They discover that the interconnectedness of the 
system makes predicting outcomes all but impossible, that even minute changes to an economic variable, for example, might have unintended and significant impacts on the social, or political parts of the system. Unlike a mind-map where there's a central idea from which the others radiate, this map has no center; no node is more important than the others. Arrange them randomly as you draw them.

\section{Observations, Objectivity and Questions}

The next step on the mapping process is to add detail to your system, and this starts with making observations about each node. We add observations simply because any exploration starts with what we know [14]. To illustrate, let's say a student is looking to explore leadership and leading in the U.S. They want to understand why (for such a simple term) there can be so many interpretations and actions. For this task they find that some basic nodes (social, political/power, economic, media and religion) seem to be at work in their open system. Given that all the nodes are equal, they can start anywhere. And the observations need not be sophisticated to be effective. In our example, a student might as well start with the economic variable observe that there are various economic classes in the US: upper, middle, and lower. Note that these are simple statements.

Students must learn to separate observations from conclusions as conclusions are not conducive to investigation. That a person makes $\$ 75,000$ a year is an observation. That the person who makes such a salary is successful, or earns too much or too little, are conclusions stemming from our definitions of "successful" and our individual perspective on what is appropriate. It's common at this stage of the process to debate what an observation is and what are a conclusion, and sometimes the choice is unclear. What is most important is to avoid forming premature judgments or making value statements. Although we may believe that our conclusions are correct, even unassailable, our conclusions are often based on hidden biases, assumptions, or misunderstandings [14].

Objectivity is a difficult task for students. When surrounded by people who is like us (when we lack cognitive diversity) it is easy to fall back on old habits of mind and become, in a way, a "lazy thinker." Among the few ground rules we demand of students during this process is that they listen carefully to what others are saying, and that they do not mock or engage in ad hominine attacks. In this effort it is important to emphasize that making an observation does not equate to endorsing a position, and that it is impossible to see a problem's full complexity if you ignore disagreeable points of view.

Students should turn their tentative conclusions into questions that open lines of inquiry. Questions can be as simple as the observations, but students should be attentive to the purpose behind each question. In the case of leadership, a student looking to establish fact might ask, "Do we teach leadership differently depending on economic status?" If she is looking to dig a little more deeply into understanding, a student might ask, "Do different economic classes define leadership differently?" Regardless, note the neutral character of the questions. As with our conclusions, our questions often reflect our worldview [16]. You should discourage students from presuming facts in evidence, such as, "Why are wealthy people better leaders?"

Lastly, guard against the tendency to skip the disciplined work of making observations. This may appear to the student an acceptable shortcut (as the goal is to form questions), but questions unmetered by observation tend to be unfocused banalities, like "do leaders make more money?" or bent on solutions, such as "how do leaders make more money".

\section{Finding the Connections}

As students develop the observations and questions for these different variables/nodes, they will likely begin seeing how they connect or influence each other. Once again it is important to form these connections as questions. Let's say next to the student's economic node they have another node called "social." In the social node they've observed that the US has as many as five generations of people living and working together and they have asked, "do different generations see leadership and leading in the same way?" We now have lines of investigation for both the economic and the social variables, but drawing a line between the two nodes we might further ask, "Does economic status of an age group affect how they see leaders and leading?" Or in simpler terms, "Do the views of these older 'leaders', the ones who tend to have money and hold positions of authority, artificially constrain the thinking of the next generation?" Once started, it does not take long for a student to see dozens of connections from and between income brackets, age, community and educational experiences, religious traditions, or media consumed.

Whereas our earlier questions led us to find facts or see barriers to understanding within each part of the system, these questions help identify the problem's center of gravity, a term coined in the 19th century for military planners that identifies the hub upon which many other things depend [17]. While not a magic talisman that provides "the" answer, finding a problem's center of gravity concentrates effort and husbands scarce resources [18]. For students acting as systems thinkers it serves a similar purpose, and lessens the possibility that they succumb to the temptation to approach the problem piecemeal and through its individual parts.

\section{Issue Mapping is also about shared understanding between stakeholders}

Students can produce an issue map as an individual assignment, but the process works best when it involves multiple stakeholders working together to make the observations and 
form questions. To be most effective, this co-creation and shared understanding starts with true cognitive diversity, meaning "cognitive and behavioral differences - differences in how people solve problems, make predictions, and behave in strategic settings. Not personality. Not identity" [19]. As teams collaborate toward identifying observations and questions, they must work through different perceptions, how people infer different meaning from words with common definitions. In doing so they begin to forge a true shared understanding of the problem [10].

Although we describe issue mapping as social activity, at QU this is also an individual assignment. To resolve the conflict a common seminar activity is to have students work on their maps together (at the whiteboard) before individually committing their work to paper for a culminating assignment, which at Quinnipiac is a poster and poster session.

\section{The Point, and the Poster Session}

At the end of the semester Quinnipiac conducts a week long campus-wide poster session for its FYS students to present their work to each other. As each student has been working on a particular question we designed the poster template with the issue map at the center. Students are not expected to share a solution or an answer; they are expected to exchange ideas about what they do not know and their plan for continued inquiry.

As an aside, know that in the first and second iterations of this activity, the quality of student work varied greatly. We observed that many students came with maps that were hastily assembled while others had polished work, but we were careful not to read too much into this inconsistency. As the hasty maps were not always indicative of any callous disregard for the exercise, and the polished works were not always a sign of rigor.

\section{A key point about teaching, and learning}

As you teach issue mapping, careful to not confuse a student's product with a student's learning process [20]. A student who struggles with the process and subsequently produces work that is sloppy may in the end teach more than a peer who produces a visually pleasing map early on. Mapping sometimes requires a counter-intuitive response from us. We should always demand rigor, namely that a student is "actively learning meaningful content with higher-order thinking at the appropriate level of expectation within a given context" [21] but learning is messy and we should be willing to see rigor in that mess. I invested the majority of my time helping students with their mapping, not in constructing the map.

\section{Discussion for Other uses Beside FYS}

Although we have described a process specifically designed for use in a First Year Seminar, we are also finding it applicable to specific disciplinary areas and senior capstone projects. A short sampling might include audience analysis in communications studies, mapping historical conditions that led to major events, visualizing the causes of global conflict in political science, or trying to understand the complexity of caregiver and patient relationships in a changing social context.

The bottom line is that issue mapping is a tool that offers a framework for students learning how to wrestle with complexity. It is about applying a simple problem structuring tool built around observations and questions, one that is designed to promote habits of inquiry, integration and communication. Regardless of where the issue mapping tool is applied, our primary driver is that students recognize that accumulating facts and content may bring a sense of knowing, but that the educated person approaches and responds to the unknown through a process of inquiry and integration. We believe these habits of mind will provide our students with competitive advantages as they travel through their life experiences.

Issue mapping is one strategy we have implemented at Quinnipiac University as a tool to help our students begin the process of developing the ability to understand and manage complex situations. It is by no means the only strategy that allows for this, nor would we argue it is the best. Rather, it is a model we have invested time and energy in and one that seems to work well for our students. As the next several years go by, we will continue to modify the class so that we best meet the goals of developing students who can think and who can consider multiple perspectives and that can deal with uncertainty.

\section{References}

1. Senge PM (1990) The fifth discipline: The art and practice of the learning organization (1st ed.). New York, USA.

2. Perry M (2014) Fortune 500 firms in 1955 vs. 201489 are gone and were all better off because of that dynamic creative destruction.

3. Arbesman S (2012) Be Forewarned: Your Knowledge is Decaying.

4. Powell WW, Snellman K (2004) The knowledge economy. Annual Review of Sociology 30(1): 199-220.

5. Hart Research Associates (2013) It takes more than a major: Employer priorities for college learning and student success. Liberal Education 99(2): 22 .

6. Prince MJ, Felder RM (2006) Inductive teaching and learning methods: Definitions, comparisons, and research bases. Journal of Engineering Education 95(2): 123-138.

7. Horst WJ Rittel, Melvin M Webber (1973) "Dilemmas in a General Theory of Planning,". Policy Sciences 4(2): 155-169.

8. Ruggiero VR (1988) Teaching thinking across the curriculum. New York, USA.

9. Heifetz RA, Grashow A, Linsky M (2009) The practice of adaptive leadership: Tools and tactics for changing your organization and the world. Boston Mass: Harvard Business Press, USA.

10. Cronin K, Midgley G, Jackson LS (2014) Issues mapping: A problem structuring method for addressing science and technology conflicts. European Journal of Operational Research 233(1): 145-158. 
11. Córdoba-Pachón J (2011) Abstracting and engaging: Two modes of systems thinking education. INFORMS Transactions on Education 12(1): 43-54.

12. Willingham DT (2008) Critical thinking: Why is it so hard to teach? Arts Education Policy Review 109(4): 21-32.

13. Benassi VA, Overson CE, Hakala CM (2014) Applying science of learning in education: Infusing psychological science into the curriculum. Retrieved from the Society for the Teaching of Psychology web.

14. Bransford J (2000) How people learn: Brain, mind, experience, and school (Expand ed.). Washington, D.C: National Academy Press, US.

15. US Joint Chiefs of Staff (2011) Joint Operational Planning. Joint Publication, Joint Chiefs of Staff, Washington, USA.

16. Duarte JL, Crawford JT, Stern C, Haidt J, Jussim L, et al. (2015) Political diversity will improve social psychological science. Behavioral and Brain Sciences 38: 1-54.

This work is licensed under Creative Commons Attribution 4.0 License

DOI:10.19080/PBSIJ.2017.04.555636
17. Clausewitz CV (1976) On War. (M. Howard \& P. Paret, Trans.). Princeton, Princeton University Press, USA.

18. Allen CD, Cunningham GK, Klinger J (2009) Systems thinking for strategic leaders. Army War College Carlisle Barracks PA.

19. Page SE (2014) Where diversity comes from and why it matters? European Journal of Social Psychology 44(4): 267-279.

20. Soderstrom NC, Bjork RA(2015) Learning versus performance: An integrative review. Perspectives on Psychological Science 10(2): 176199.

21. Draeger J, del Prado Hill P, Mahler R (2015) Developing a student conception of academic rigor. Innovative Higher Education 40(3): 215228.

Your next submission with Juniper Publishers
will reach you the below assets
- Quality Editorial service
- Swift Peer Review
- Reprints availability
- E-prints Service
- Manuscript Podcast for convenient understanding
- Global attainment for your research
- Manuscript accessibility in different formats
( Pdf, E-pub, Full Text, Audio)
- Unceasing customer service
Track the below URL for one-step submission
https://juniperpublishers.com/online-submission.php

